\title{
eSport: Friend or Foe?
}

\author{
Remco Polman ${ }^{1}$, Michael Trotter ${ }^{1,2}$ Dylan Poulus ${ }^{1,2}$, \& Erika Borkoles ${ }^{3}$ \\ ${ }^{1}$ Queensland University of Technology, School of Exercise and Nutrition Sciences \\ ${ }^{2}$ Queensland University of Technology, eSport Centre \\ ${ }^{3}$ Queensland University of Technology, School of Public Health and Social Work
}

\begin{abstract}
Sport is a growing industry in terms of its players, spectators and economic value and will be included in the 2024 Paris Olympics. Although interest initially in eSport was mainly associated with younger males, eSport has the potential to bring about health behaviour change across the wider population of users. This paper discusses the potential of eSport to influence health outcomes across the lifespan and address some of the major barriers that will help individuals to change their physical activity behaviours. Considering the exponential growth in eSport, it is important for academics and policy makers to recognise and seize the opportunities arising from eSport.
\end{abstract}

Keywords: eSport, public health, behavioural change, implementation.

\section{Introduction}

Dating back to a 1999 press release by the Online Gamers Association [1] the term eSport ${ }^{1}$ (also referred to as electronic sports; competitive video gaming; cyber sports) is used to describe the competitive and organised playing of video games [2]. This rapidly growing industry sector has the potential to influence and reach millions of (younger) individuals. For example, it is anticipated that by 2020 this industry's worth will exceed 23.5 billion USD [3]. Currently, around 385 million people watch eSport (either online or in stadiums) worldwide and this is predicted to grow to 589 million by 2020 [4]. Its popularity is also indexed by its

\footnotetext{
${ }^{1}$ eSports can be categorised into: First Person Shooter (FPS), Real Time Strategy (RTS) and Multiplayer Online Battle Arena (MOBA) games.
} 
inclusion in the 2024 Paris Olympics and by the significant increases in prize money on offer for participants [4].

Whether eSport is a 'sport' and its players 'athletes' is still equivocal. There is also no generally accepted definition of eSport. However, this is not pertinent to the current paper. In contrast to eSport, video gaming has received significant attention from the scientific community, whereas eSport research is still in its infancy. eSport research to date has mainly concentrated on the economic and game developmental aspects. For example, a recently launched eSport academic programme at Staffordshire University in the UK is mainly focussed on event management of eSport.

\section{$2 \quad$ Video gaming vs eSport research}

Contrary Serious Gaming, video gaming research has mainly focussed on the potential negative consequences of excessive playing of video games, its association with video game addiction, and the potential negative consequences of violence. In fact, video game addictions and its associated behavioural consequences are now included in the $5^{\text {th }}$ edition of the Diagnostic and Statistical Manual of Mental Disorders under the umbrella term of "Internet Gaming Disorders” [5] as an area for further research.

The association between video game addiction, mental, physical, and social health as well as academic/cognitive functioning is still equivocal, as is the research on violence. A meta-analysis by Ferguson et al. [6] provided some evidence that video game addiction has the strongest negative effect on social functioning of gamers. Although associations have also been found between video game addiction and lower mental (stress, anxiety, depression, suicidal ideation) and physical (physical inactivity, BMI, sleep) health. Most of this work, however, is cross-sectional, not allowing to establish cause and effect, and many of such research are methodologically flawed as they did not control for potential confounding 
factors (e.g., playing time). Importantly, most research did not distinguish between (intense) engagement and addiction [7]. The former is likely to have no negative consequences but a curiosity and prioritisation of gaming as a hobby or lifestyle choice [8].

The limited research in eSport, on the other hand, has focussed on differences and similarities between eSport and traditional sport [2, 9]. In particular, psychological similarities could indicate that sports psychology practices and interventions would also be applicable to eSport. For example, Himmelstein and colleagues [10] interviewed eSport athletes (League of Legends) to examine the mental skills they currently utilise and the mental obstacles or barriers they encounter. Our own research is also aligned with the more traditional sport research, which examines psychosocial factors that determine success in eSport. This is an important 'paradigm shift' and has the potential to enhance the focus on the prospective benefits of eSport rather than highlighting the presumed negative consequences.

\section{3 eSport for Public Health?}

Whereas Serious Games are generally developed with altruistic and humane motives to, for example, help with the rehabilitation of stroke patients or improve the learning of children with cerebral palsy, eSports have been developed to gain commercial success. Serious Gaming is often aimed at improving public health outcomes for specific populations, but so far improvements are limited, probably due the relatively small number of individuals making use of the games and the difficulty of its implementation across settings.

Considering the significant number of individuals playing and watching eSport there is a real opportunity to influence health behaviours. Although eSports appeal currently more to certain segments of the population (younger and male) this is, like traditional sport, likely to change over time. An important question, which arises from this is how eSport 
manufactures and organisations can work together with, for example, behaviour change specialists, to tackle important public health issues using eSport as a vehicle?

Change in physical activity and sedentary behaviour are two topics which comes to mind when considering the wider implications of eSport participation. Lack of physical activity and sitting too much is a worldwide problem [11] and has been shown to have detrimental physical, psychosocial and cognitive consequences and is one of the most important public health concerns with increasing individual, societal and economic cost [12]. A lack of physical activity is for example, associated with obesity in children and adolescents [13]. Childhood obesity predicts development of chronic conditions in adulthood and is associated with poor fundamental motor skills. Obesity, low physical fitness and poor fundamental movement skills during childhood and adolescence are all associated with poor cognitive development (e.g. language) and academic performance [14]. Obese children are also more likely to place higher demands on educational, social, health and criminal justice systems during this time of development, which again often carries over into adulthood [15].

Of course the idea that physical and cognitive development should go hand in hand is not new. As Socrates stated (400 BC): For in everything men do the body is useful, and in all uses of the body it is of great importance to be in as high a state of physical efficiency as possible. Why, even in the process of thinking, in which the use of the body seems to be reduced to a minimum, it is a matter of common knowledge that grave mistakes may often be traced to bad health. Such a view opposes the pervasive Decartian dualism viewpoint, which has been prevalent across western societies. In contrast, psychology suggest that a holistic development of a sound body will enhance the development and functioning of the mind [16].

Being a competent mover is an important determinant of physical activity and play behaviour in young people [17]. A physically active lifestyle, in turn, builds resilience to 
mental, social, and physical ill health. Through eSports, and making use of immersive environments and sensor technology, it might be possible to assist children and adolescents to develop these fundamental movement skills [18]. Mastering a range of motor skills through playing eSport could help overweight children to gain confidence in their movement skills when participating in a wide variety of physical activities in multiple environments, which will ultimately contribute to the healthy development of the whole person.

Video game and eSport developers have been consistently applying psychological principles to their designs in order to 'hook' players to their games. These or other strategies (e.g., priming) could also be used to initiate and maintain health behaviour change when designing eSport games in the future. Because of the design of video games and eSport games are divergent, researchers need to understand how to apply behaviour change techniques to motivate the wider population to engage with health behaviours and movement skills learning through eSport.

Similar to traditional sport, to excel at the highest level in eSport it is likely to be associated with being fit and healthy (something we currently exploring in our research). If this is the case, strategies might be developed to help aspiring eSport athletes to develop 'eSport fitness'. It is probable that eSport athletes’ fitness will vary during its development and increase with eSport's professionalization. Such a development would be similar to what happened historically in golf. The significance of physical training and fitness in professional golf has only emerged from the 1990s when Tiger Woods started to pay attention to being physically fit and athletic. Most golfers now have a physical trainer and spend significant amount of their training in the gym. Playing eSport at the elite level requires the ability to sustain high levels of attention, respond as quickly as possible to stimuli, and make numerous important decisions under time pressure. In addition, with the development of more immersive environments various physical skills might also become important to success. 
Therefore, current and future skill requirements in eSport will necessitate players (or athletes) to be fit, healthy and movement competent in order to perform at the highest level of competition, just like in the physical environment during the Olympics.

Currently, it is unknown how individuals perceive the difference of creating a professional high sporting performance in the virtual versus physical environments. Our research team is investigating such differences, including the transitioning from virtual to physical, which is the crucial element of playing eSport and its transference to physical health. We hypothesise that initially, playing eSport might be the most beneficial for the development of cognitive skills. In the study by Himmelstein and colleagues [10], players reported to develop self-regulatory skills and a growth mindset. Such skills are not only important for optimal eSport performance, but are also transferable to other domains and highly sought after in the world of work [19].

\section{4. $\quad$ eSport and Implementation Science}

While the potential for using eSport to bring about health behaviour change is apparent, the way this might be approached needs some careful consideration. There are many factors that influence the transfer of an evidence based research into daily practice and ultimately to population health. There needs to be a careful consideration and research into the adoption and uptake of eSport for health benefits both from the users' and the designers' perspectives. From the outset of the planning of using eSport for changing physical activity behaviours in children/adolescents an implementation logic model will need to be designed to aid the understanding of the underlying processes of adoption and maintenance of learned skills.

\section{$5 \quad$ Roadblocks in doing eSport research}


Like all new endeavours conducting research in eSport or using eSport to implement public health strategies will not be without obstacles. To date we have identified 3 categories of potential problems: Commercial protectionism, research weariness, and ethical issues.

Commercial protectionism: It is understandable that the makers of the different eSport games try to protect their brand. However, like traditional sports, there will be a need to be more open and transparent in its governance. Despite many traditional sports not being structured and managed according to best practice principles, ultimately, traditional sport has become part of the political landscape. For example, the Australian Government recently presented their Sport 2030 plan [20]. This has resulted in national or local governments across many countries providing significant support to traditional sport in terms of building infrastructure or organising major events. In addition, traditional sport is now increasingly being used to promote health behaviour change. Despite eSport being recognised in some countries (e.g., Korea and Denmark) if it wants to become 'mainstream', it will also need to develop an independent and autonomous administration for one or multiple eSports internationally [21]. This also requires compliance with international sport regulations on aspects like doping and betting whilst at the same time enhancing legitimacy and augment its potential for sponsorship and governmental support [21].

Research weariness: Within the computer gaming community there has been a weariness to research potentially because of its emphasis on the negative consequences in terms of excessive play and/or violence. Over the years, we have found more difficulties with participant recruitment either during events or at relevant online forums. Some of the responses to attempted recruitment, online or in person, have been hostile to say the least. As such we are developing alternative strategies to engage the eSport community to participate in research. For example, team owners have been supportive of our work and we are trialling 
other online methods (e.g., through youtube channels) to interest and involve the eSport community.

Ethics: eSport is an important activity for many adolescents. Their preferred way of communication, and thus future data collection, is through online or electronic means. This, however, creates a number of ethical barriers. For example, in Australia the age at which adolescents can consent is normally 18 years. This makes it extremely challenging to involve younger eSport players in our studies. This is not a request to abandon consent from either participants or their guardians. However, we have to think creatively to involve as many individuals as possible to reap future benefits. In addition to this, many eSports collect significant amounts of data of their players, with virtually every move and keystroke being recorded. This also raises questions of who owns the data and how we can use this future research purposes?

\section{Conclusion}

In this paper, we have provided a case to use eSport as a potential vehicle to influence health behaviours. We acknowledge that there are significant obstacles which we have to overcome. However, the accelerated growth of eSport in terms of its participants, spectators, and economic value makes it a domain which cannot be ignored by researchers, public servants and politicians. In addition, it has the potential to reach groups in society which to date have been hard to influence. Most of our interventions to make children and adolescents more active have failed. We are optimistic and believe that eSport is our friend and an important vehicle to stop that trend.

\section{References}

1. Wagner, M. G. (2006). On the Scientific Relevance of eSports. Symposium conducted at 2006 International Conference on Internet Computing \& Conference on Computer Games Development, Las Vegas, Nevada.

2. Jenny, S.E., Manning, R.D., Keiper, M.C., \& Olrich, T.W. (2017). Virtual(ly) athletes: Where eSports fit within the definition of 'sport'. Quest, 69(1), 1-18. 
3. Holden, J.T., Rodenberg, R.M., \& Kaburakis, A. (2017). ESports corruption: Gambling, doping and global governance. Maryland Journal of International Law, 32(1), 236-273.

4. Newzoo (2017). 2017 Global eSports market report: Trends, revenues, and audience toward 2020.

5. American Psychiatric Association. (2013). Diagnostic and statistical manual of mental disorders (5th ed.), Washington: APA.

6. Ferguson, C. J., Coulson, M., \& Barnett, J. (2011). A meta-analysis of pathological gaming prevalence and comorbidity with mental health, academic and social problems. Journal of psychiatric research, 45(12), 1573-1578.

7. Charlton, J. P., \& Danforth, I. D. (2007). Distinguishing addiction and high engagement in the context of online game playing. Computers in Human Behavior, 23(3), 15311548.

8. Seok, S. \& DaCosta, B. (2014). Distinguishing addiction from high engagement: an investigation into the social lives of adolescent and young adult massively multiplayer online game players. Games and Culture, 9(4), 227-254.

9. Schaeperkoetter, C.C., Mays, J., Hyland, S.T., Wilkerson, Z., Oja, B., Krueger, K., Christian, R., \& Bass, J.R. (2017). The 'new' student-athlete: An exploratory examination of scholarship eSport players. Journal of Intercollegiate Sport, 10, 1-21.

10. Himmelstein, D., Liu, Y., \& Shapiro, J. L. (2017). An exploration of mental skills among competitive league of legend players. International Journal of Gaming and ComputerMediated Simulations, 9(2), 1-21.

11. Guthold, R., Stevens, G.A., Riley, L.M., \& Bull, F.C. (2018). Worldwide trends in insufficient physical activity from 2001 to 2016: A pooled analysis of 358 population based surveys with 1.9 million participants. Lancet Global Health (available ahead of print).

12. Ding, D., Lawson, K.D., Kolbe-Alexander, T.L., Finkelstein, E.A., Katzmarzyk, P.T., van Mechelen, W., \& Pratt, M. (2016). The economic burden of physical inactivity: A global analysis of major non-communicable diseases. Lancet, 388, p1311-1324.

13. Hills, A.P., Andersen, L.B., \& Byrne, N.M. (2011). Physical activity and obesity in children. British Journal of Sports Medicine, 45(11), 866-870.

14. Kantomaa, M.T., Stamatakis, E., Kankaanpaa, A., Kaakinen, M., Rodriguez, A., Taanila, A., Ahonen, T., Jarvelin, M.R., \& Tammein, T. (2013). Physical activity and obesity mediate the association between childhood motor function and adolescent academic achievement. PNAS, 110(5), 1917-1922.

15. McDaid, D. (2011). Making the long-term economic case for investing in mental health to contribute to sustainability. Brussels: EU.

16. Forstmann, M., Burgmer, P., \& Mussweiler, T. (2012). The mind is willing, but the flesh is weak: The effects of mind-body dualism on health behaviour. Psychological Science, 23(10), 1239-1245.

17. Rudd, J., Barnett, L., Farrow, D., Berry, J., Borkoles, E., \& Polman, R.C.J. (2017). Effectiveness of a 16 week gymnastic curriculum at developing movement competence in children. Journal of Science and Medicine in Sport, 20(2), 164-169.

18. Bisi, M.C., Panebionco, P., Polman, R., \& Stagni, R. (2017). Objective assessment of movement competence in children using wearable sensors: An instrumented version of the TGMD-2 locomotor subset. Gait \& Posture, 56, 42-48

19. Bloomberg next (2018). Building tomorrow's talent: Collaboration can close emerging skill gap. The Bureau of National Affairs Inc.

20. Sport Australia (2018). Sport 2030: Participation, Performance, Integrity, Industry. Canberra: Australian Government. 
21. Jonasson, K. \& Thiborg, J. (2010). Electronic sport and its impact on future sport. Sport in Society, 13(2), 287-299). 